\title{
Sulfonated Polystyrene Copolymer: Synthesis, Characterization and Its Application of Membrane for Direct Methanol Fuel Cell (DMFC)
}

\author{
S. Mulijani, K. Dahlan, and A. Wulanawati
}

\begin{abstract}
A novel Sulfonated Polystyrene (PSS) has been synthesized by sulfonation polystyrene waste for a comparative study of proton exchange membranes (PEM) that is intended for fuel cell applications. The degree of sulfonation (DS) of the sulfonated PS was determined using titration method. We systematically investigated the water uptake, proton conductivity, and methanol permeability of the cross-linked membranes. The mass averaged molecular weights Mw of PSS was estimated from intrinsic viscosities measured in sulfuric acid solutions. A related homopolymer was characterized by Fourier transform infrared (FT-IR) and nuclear magnetic resonance (NMR) spectroscopy. The structures of PSS were elucidated, and the effect of sulfonation level on the PSS FT-IR spectrum was studied. PSS membrane surface morphology was investigated by SEM and AFM.
\end{abstract}

The highest of proton conductivity of the membrane in the temperature range of $25-750 \mathrm{C}$ was found to be $3.8 \mu \mathrm{S} / \mathrm{cm}$

Index Terms-AFM, FT-IR, fuel cell, polystyrene sulfonated, SEM.

\section{INTRODUCTION}

Fuel cells, due to their high efficiency, low environmental impact and flexible application, have been gaining much attention as a promising alternative to replace conventional fossil fuel systems [1]. In fact, several types of fuel cells have been commercialized, such as proton exchange membrane fuel cell (PEMFC) which utilizes hydrogen as fuel [2]. PEMFC are among the most promising electrochemical devices for convenient and efficient power generation. The proton exchange membrane (PEM) is a key component in the system, which functions as an electrolyte for transferring protons from the anode to the cathode as well as providing a barrier to the passage of electrons and gas cross-leaks between the electrodes. Currently, the most commonly used PEM for both hydrogen $\left(\mathrm{H}_{2}\right.$-PEMFC) and direct methanol fuel cells (DMFC) are perfluorinated copolymers such as Nafion ${ }^{\circledR}$, which have high hydrolytic and oxidative stability and excellent proton conductivity. However, the perfluorinated polymers have three major drawbacks: very high cost; loss of conductivity at high temperature $\left(>80^{\circ} \mathrm{C}\right)$;

Manuscript received March 5, 2013; revised May 8, 2013.

S. Mulijani is with Department of Chemistry Bogor Agriculture university, Darmaga Campus, Bogor, Indonesia (e-mail: smulijani@ipb.ac.id, janism67@gmail.com).

K. Dahlan is with Department of Physics, Bogor Agriculture University, Darmaga Campus, Bogor, Indonesia (e-mail: kiagusdahlan@)ipb.ac.id).

A. Wulanawati is with Department of Chemistry Bogor Agriculture university, Darmaga Campus, Bogor, Indonesia (e-mail: armiwu@ipb.ac.id). and high methanol permeability, that hinders their further application [3].

Various efforts were made along different directions purposed to develop alternative membranes which are more economical, have higher operating temperatures, as well as higher proton conductivity and low methanol permeability. Many promising polymers are based on aromatic thermoplastics, such as poly (ether ether ketone) (PEEK); poly (ether sulfone) (PES); polybenzimidazole, (PBI); and other poly (aryl ether ketone), PAEK. The aromatic polymers possess excellent chemical resistance, high thermo-oxidative stability, good mechanical properties and low cost. These aromatic polymers must be sulfonated in order to be used as PEM material [4]-[7].

Sulfonation is a well-known process to increase the hydrophilicity and proton conductivity of polymer by attaching sulfonic groups to the polymers' chain. The attached sulfonic groups can offer and retain relatively higher water due to the enhanced antifouling capacity and favorable hydrodynamic environment of the membrane, which is also a very important mechanism for proton conducting. However, in order to achieve sufficient proton conductivity, the sulfonated aromatic polymer membranes should possess a high sulfonation level [8]. The increasing sulfonation level of the membranes leads to overfull swelling in water, as well as high methanol crossover [9]. Ideas to overcome these issues include preparing blended membranes, hybrid and/or composite membranes, grafted and cross-linked membranes, and pore-filling electrolyte membranes.

Cross-linking is an efficient way to limit excess water uptake and methanol crossover. It also improves the stability and mechanical properties of the membranes. Han et al. 2010 reported carboxyl-terminated benzimidazole-assisted cross-linked sulfonated poly (ether ether ketone) (SPEEK) membranes that were prepared by a heating method, and the resulting membranes exhibited enhanced performance over uncross-linked membranes [10]. Moreover, the membrane properties can be further improved by introducing benzimidazole ring groups into SPEEK. Polybenzimidazole is a high performance polymer that exhibits good thermal and mechanical properties, as well as benzimidazole rings that possess both donor and acceptor hydrogen bonding sites due to their amphoteric nature [11]-[13].

In relation to this research on proton exchange membrane fuel cell, we would like to utilized the abundant waste of polystyrene to become environment friendly and high economical value. Polystyrene has an aromatic group and a high performance polymer those also good thermal and mechanical properties. Synthetic methods have been developed to incorporate stryrene as a graft on to a polymer 
back bone. The study will be synthesized membrane and continued for investigation of membrane function as PEMFC.

\section{MATERIALS AND METHOD}

\section{A. Sulfonation of Polymers}

Typically $20 \mathrm{~g}$ of PS from Styrofoam waste was dried in a vacuum oven at $100{ }^{\circ} \mathrm{C}$ and then dissolved in $500 \mathrm{ml}$ of chloroform and added $\mathrm{H}_{2} \mathrm{SO}_{4}$ sulfuric acid fume at room temperature under vigorous stirring and held for the desired time ranging from $1 \mathrm{~h}$ to $3 \mathrm{~h}$. In some cases the temperature was increased up to $50-80{ }^{\circ} \mathrm{C}$ and the reaction time decreased correspondingly down to several hours. To stop sulfonation reaction the polymer solution was decanted into a large excess of ice-cold water under continuous mechanical agitation. The polymer precipitate was filtered and washed several times with distilled water until the $\mathrm{pH}$ was neutral. The polymer was then dried under vacuum for $8-10 \mathrm{~h}$ at $25-100{ }^{0} \mathrm{C}$. The degree of sulfonation was determined by titration; $1-2 \mathrm{~g}$ of the SPS was placed in $0.5 \mathrm{M}$ aqueous $\mathrm{NaOH}$ and kept for 1 day. The solution was back titrated with $0.5 \mathrm{M} \mathrm{HCl}$ using phenolphthalein as an indicator.

\section{B. Membranes Preparation}

Membranes were prepared by dissolving a known amount of sulfonated PS and in dichloridemethane with $10 \%(\mathrm{w} / \mathrm{v})$ composition under constant stirring. Resulting solution was casted in the form of thin film on a cleaned glass plate and dried at $60{ }^{\circ} \mathrm{C}$. These membranes were conditioned in $0.10 \mathrm{M}$ $\mathrm{HCl}$ solution and $0.10 \mathrm{M} \mathrm{NaOH}$ solution alternately several times and then equilibrated with experimental solution before being subjected to physicochemical and electrochemical studies.

\section{Morphology and Topography of Membrane Studies}

Morphology and topography of membrane were evaluated by Scanning Electron Microscope (SEM) and Atomic Force Microscope (AFM). For SEM, sample with gold sputter coatings was carried out on the desired membrane samples at pressure ranging between 1 and $0.1 \mathrm{~Pa}$.

\section{Water Content Measurements}

For the measurement of water content, the membrane samples $(5 \times 5 \mathrm{~cm})$ were immersed in distilled water for $24 \mathrm{~h}$, and then their surface was wiped with filter paper and wet membrane weighed. Thickness of wet membrane was determined by means of a digital micrometer and membrane density for wet membrane by dividing the wet membrane weight by volume. Following this, wet membrane was dried at fixed temperature of $60^{\circ} \mathrm{C}$ to constant weight. Thickness of dry membrane was also determined in a similar manner and its density estimated. Water content of the membranes was determined in turn of water concentration in the membrane phase.

\section{E. Membrane Potential and Membrane Conductance}

Transverse proton conductivities of the PSS membranes were measured by AC impedance spectroscopy over a frequency range of $1-107 \mathrm{~Hz}$ with $50-500 \mathrm{mV}$ oscillating voltage, using a Solatron 1260 gain phase analyzer. Films having $13 \mathrm{~mm}$ diameter, sandwiched between two stainless steel block electrodes with $3 \mathrm{~kg} / \mathrm{cm}^{2}$ pressure, were placed in an open, temperature-controlled cell. The films were previously hydrated by immersion for $24 \mathrm{~h}$ at room temperature. The conductivity $\sigma$ of samples in the transverse direction was calculated from the impedance data, using the relationship $\sigma=d / R S$, where $d$ and $S$ are the thickness and face

Area of the membrane sample, respectively, and where $R$ was derived from the low intersection of the high frequency semi-circle on a complex impedance plane with the $\operatorname{Re}(Z)$ axis. The impedance data were corrected for the contribution from empty and short-circuited cell.

\section{RESULTS AND DISCUSSION}

\section{A. Sulfonation Process}

Sulfonation process has been conducted several times by varying the molar ratio of the polymer to sulfonating agent. Suitable operating conditions of the sulfonation process were identified by trial and error.

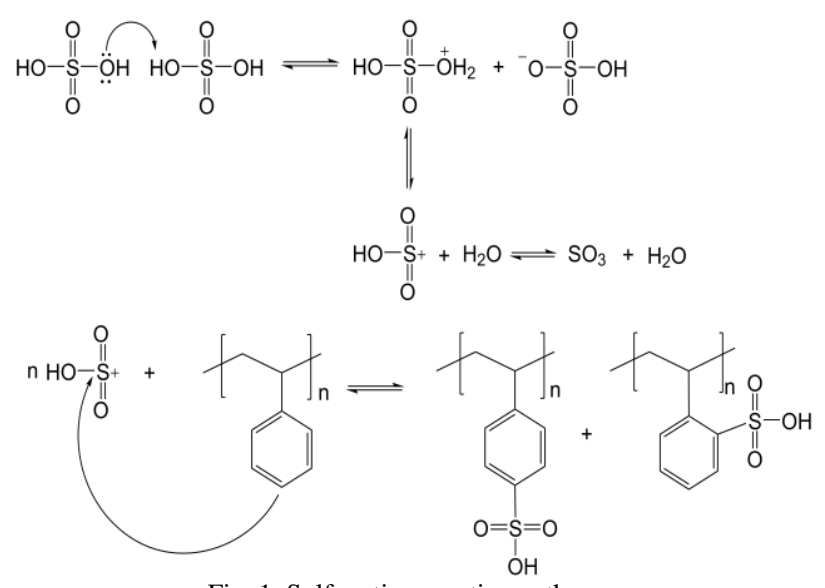

Fig. 1. Sulfonation reaction pathway.

Fig. 1 expressed the pathway of sulfonation reaction towards polystyrene which content aromatic compound. In this electrophilic aromatic substitution, sulfur trioxide is the electrophile generated from concentrated sulfuric acid (or fuming sulfuric acid) when its heated. Benzene as aromatic substrate in polystyrene is attacked by sulfur trioxide and produced polystyrene sulfonic acid.

Three respective sulfonated polystyrene membranes (PSS1, PSS2, PSS3) were then characterized and studied as shown in Table I.

TABLE I: SULFONATIION PROCESS OPERATING CONDITION ARRANGEMENT

\begin{tabular}{llll}
\hline & $\begin{array}{l}\% \\
\text { Reaction } \\
\text { Temperature }\end{array}$ & $\begin{array}{l}\text { Weight of } \\
\mathrm{H}_{2} \mathrm{SO}_{4}\end{array}$ & $\begin{array}{l}\text { Degree of } \\
\text { sulfonation (DS) }\end{array}$ \\
\hline PSS1 & $25-28^{\circ} \mathrm{C}$ & 5.0 & 35.09 \\
PSS2 & $25-28^{\circ} \mathrm{C}$ & 10.0 & 42.26 \\
PSS3 & $25-28^{\circ} \mathrm{C}$ & 15 & 48.15 \\
\hline
\end{tabular}

Significant correlation of degree of sulfonation with concentration of sulfuric acid was revealing (Table I). The study indicated that increase of $\mathrm{SO}_{3} \mathrm{H}$ will affect the value of DS. The molecular weight of PSS membrane was evaluated 
following viscosity methods and it's resulted as $9.1 \times 10^{4} \mathrm{~g}$ $\mathrm{mol}^{-1}$.

\section{B. FTIR Study Result}

Sulfonation process of the PS was confirmed qualitatively by FTIR. The FTIR spectra of PS and its sulfonated derivatives are depicted in Fig. 2. The process, which occurs exclusively in the phenyl rings should be manifested by the appearance of new vibration characteristic of sulfonic acid groups; by changes in the aromatic $\mathrm{C}-\mathrm{H}$ out of plane bending region and perhaps by splitting of some bands (e.g. the $\mathrm{C}-\mathrm{O}$ stretch of the substituted rings), which is due to the reduced symmetry and direct influences of sulfonic acid groups vibration frequencies after the sulfonation process occurred [14].

Significant differences in FTIR spectra of sulfonated PS were observed compared to pure PS. The peak identified at $1500 \mathrm{~cm}^{-1}$ proved the presence of $\mathrm{C}-\mathrm{C}$ aromatic ring in the PS, which referred to the 2, 4-substitution aromatic ring that meant only first substitution involved in this study.

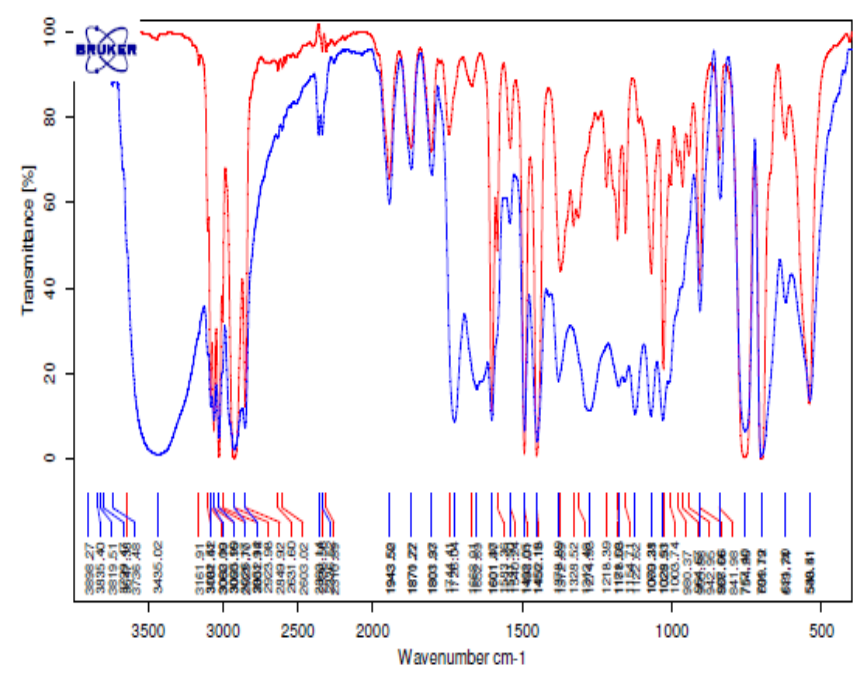

Fig. 2. FTIR Spectra of PSS.

The first type substitution reaction is more favorable since results showed that sulfonated PS became water-soluble when the sulfonation degree was approaching $100 \%$. Evidently, the second type substitution sulfonated PS was not suitable to be used as membrane materials. Therefore, the first type substitution was used in this study. The sulfonation process decreased the intensity of the aromatic $\mathrm{C}-\mathrm{C}$ vibration and the peak was observed to split to two absorption band at 1495 and $1475 \mathrm{~cm}^{-1}$. It was found that these two bands increase as the concentration of sulfonic acid group in the sulfonated PS membranes increases. A new absorption band occurred at $1029.39 \mathrm{~cm}^{-1}$ dan 1178.03, 1255, 1090 and 1020 $\mathrm{cm}^{-1}$ upon sulfonation indicated the sulfonic acid groups in PS. In summary, the changes observed in the FTIR spectra indicated the presence of $-\mathrm{SO}_{3} \mathrm{H}$ groups.

\section{IH NMR Study Result}

${ }^{1} \mathrm{H}$ NMR was employed in order to rationalize the observed effects (Fig. 3). It was found that PSS samples prepared using dichloromethane as the solvent have a single peak at $2.0 \mathrm{ppm}$. This peak assigned to $-\mathrm{SO}_{3} \mathrm{H}$ group and absolutely polystyrene sulfonated has been occurred.
Another important observation is a broad peak triplet at 7.2 ppm indicated aromatic group, and a doublet peak at $2.6 \mathrm{ppm}$ and $1.25 \mathrm{ppm}$ assigned chain of polystyrene. In the presence of water, $-\mathrm{SO}_{3} \mathrm{H}$ inevitably forms hydrogen bonds with its oxygen and the NMR shift of this proton should be dependent on the electron density around the $-\mathrm{SO}_{3} \mathrm{H}$ hydrogen. Therefore, this chemical shift is dependent on the hydrogen bond strength, on temperature, concentration and on intra- or inter-molecular interactions. Diluting the sample, for example, is spacing apart the $-\mathrm{SO}_{3} \mathrm{H}$ groups on the polymer chains, resulting in weaker $\mathrm{H}$-bonding which should have the effect of increasing the electron density around the hydrogen atom, and bringing about a significant up field shift of its ${ }^{1} \mathrm{H}$ NMR absorption. That behavior was indeed observed with TMF free samples, where $-\mathrm{SO}_{3} \mathrm{H}$ water absorption revealed a peak at 5-7 ppm, the position of which depended on concentration.

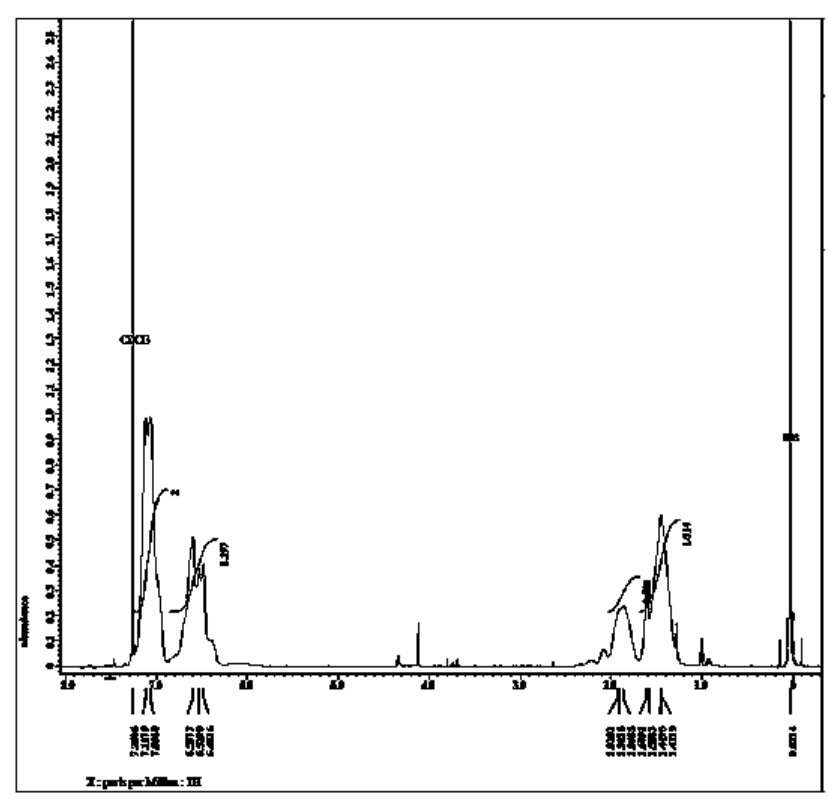

Fig. 3. ${ }^{1} \mathrm{H}$ NMR spectrum of membrane PSS.

\section{AFM Study Result}

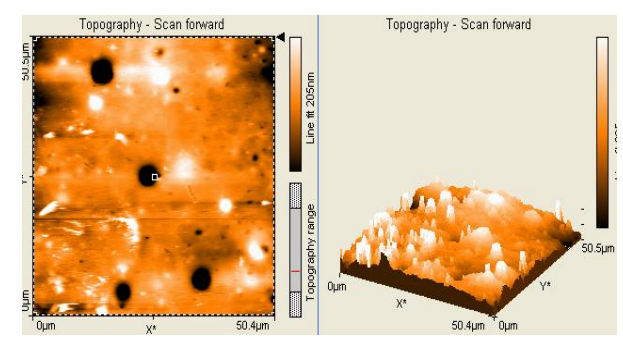

(a)

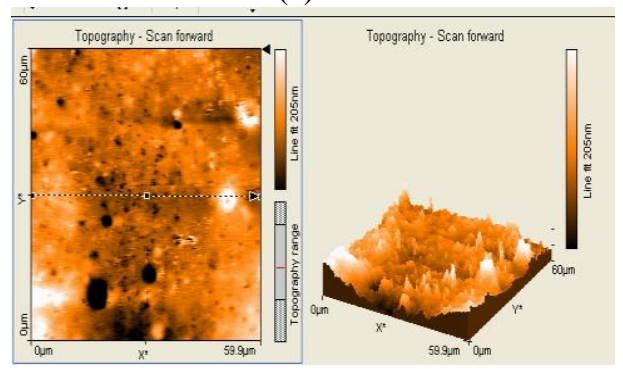

(b)

Fig. 4. AFM Photograph (a) PSS Membrane before fuel treatment DMFC process; (b) PSS Membrane after treatment DMFC process. 
In another study, the topography characterization of the membranes before and after the fuel cell process treatment was done by means of AFM. It was clearly observed that the fuel cell process treatment affected the surface morphology of the PSS asymmetric membranes. Fig. 4a shows a three-dimensional AFM image of the top surface, which features a nodular structure with interconnected cavity channels running between the agglomerated nodules. Fig. $4 \mathrm{~b}$ shows, on the other hand, an AFM image of the top surface after the fuel cell process treatment. Fig. 5 explained correlation roughness and area membrane before and after treatment. The roughness of membrane before treatment showed rougher than that the membrane after treatment. This properties exposing the membrane to higher proton even for shorter times, indicating that this process depends mainly on the total amount of ionomer (proton) deposited to the system during the process treatment [15].

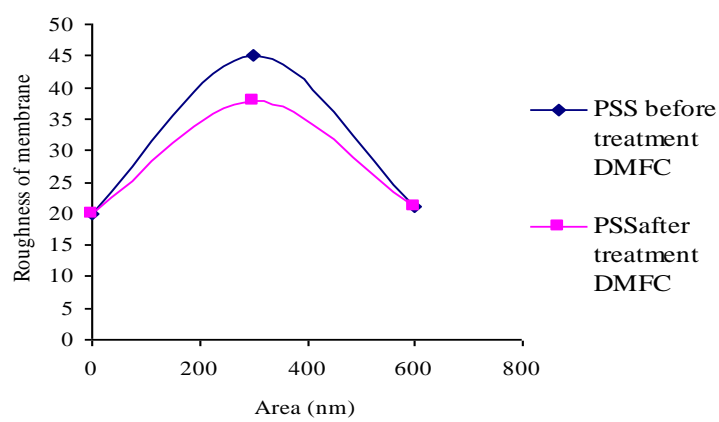

Fig. 5. Correlation between roughness and area of membrane.

\section{E. SEM Study Result}

Morphology of surface membrane was evaluated by SEM as depicted in Fig. 5. The membrane samples were fractured by keeping in liquid nitrogen and the cross-sections were observed in SEM.

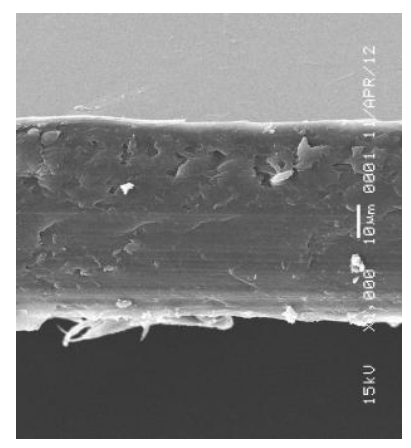

(a)

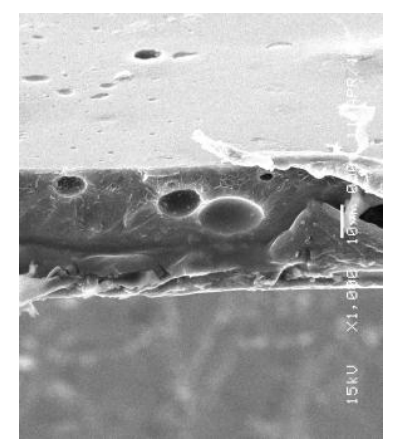

(b)
Fig. 5. Morphology of cross section membrane (a) PS and (b) PSS.

While the cross-section of the PS membrane shows compactness, PS membranes cross-sections faced that the membrane matrix is somewhat porous with few voids, which may be attributed to sulfonation reaction of PS. A gradual gain of voids in the PSS membranes with increase in the content of $\mathrm{SO}_{3} \mathrm{H}$ can also be observed.

\section{F. Proton Conductivity Study}

A representation of membrane with DS at various PS content in PSS membrane is given in Fig. 6. The conductivity $(\sigma)$ of the membrane samples in the transverse direction was calculated from the impedance data using the relation $\sigma=L$
IRS. $R$ was obtained from the intersection of the semicircles with the $\operatorname{Re}(Z)$ axis calculated using the $Z$ View software. Proton conductivity is the most essential requirement for proton exchange membranes. Without enough proton conductivity, a membrane cannot be used in fuel cell. Proton conductivity may have different values with different measuring approaches and instruments.

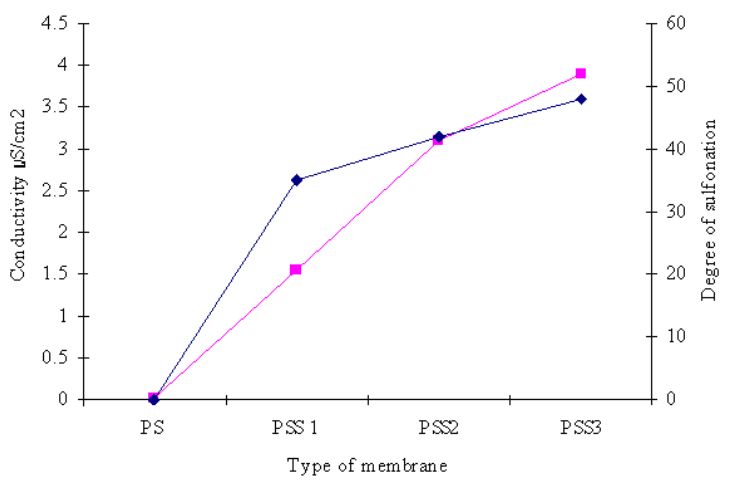

Fig. 6. Correlation of proton conductivity and DS of PSS membrane.

It has been reported that the proton conductivity depends on the DS, pre-treatment of the membrane, hydration state, ambient relative humidity and temperature [16]. The membranes also expressed with increasing DS also enhance the value of proton conductivity. For ionomeric membranes, the proton conductivity depends on the number of available acid groups and their dissociation capability in water, which is accompanied by generation of protons. According to Ismail and coworkers [17], the high ionic conductivity demonstrated by the membrane at high sulfonation level suggests that the water swollen ionic domains in the membranes pores were interconnected to form a network structure. Water molecules also dissociate acid functionality and facilitate proton transport, so the water uptake is an important parameter. This effect could be seen clearly when comparing the water uptake and proton conductivity values. When the water uptake increased, the proton conductivity is also increased. Higher water uptakes generated more solvated species, which are needed for high proton conductivity. The relative humidity during the conductivity measuring is always assumed to be $100 \%$ because the membranes were soaked in the water $24 \mathrm{~h}$ prior to the testing.

The proton conductivity was found to increase with the DS as the polymer becomes more hydrophilic and absorbs more water which facilitates the proton transport. Hence, the sulfonation raises the proton conductivity of PSS not only by increasing the number of protonated sites $\left(\mathrm{SO}_{3} \mathrm{H}\right)$, but also through the formation of water mediated pathways for protons. Ismail et al. [17] has reported that only pure SPEEK56 membrane without any addition of inorganic materials possess lower proton conductivity than Nafion 112 membrane while other membrane showed higher value of proton conductivity.

In general, it is known that the proton conductivity does not directly correlate with either water uptake or ion exchange capacity for any of the polymers applicable in fuel cell technology. Sulfonated hydrocarbon polymers usually have greater water uptake than the perfluorosulfonic polymer in order to achieve the same proton conductivity which is 
probably due to the much lower acid content in the hydrocarbon polymers than the perfluorosulfonic acid polymer (Ismail et al. 2009).

\section{G. Methanol Permeability Study Result}

Methanol permeation through ion exchange membrane from anode to cathode is very important because this phenomenon leads to a voltage drop of fuel cell and lowers the fuel utilization. Proton exchange membranes with lower methanol permeation may allow the use of methanol fuels with higher concentration that increases the energy density. The study was evaluated through qualitative method and it can be reported hat no membrane possesses high methanol permeability membrane.

\section{CONCLUSION}

Sulfonation of polystyrene was carried out and their extents of sulfonation were determined by ${ }^{1} \mathrm{H}$ NMR studies. PSS membranes were prepared with varied weight fraction of each component in the blend and were characterized in different physicochemical and electrochemical techniques. Membranes PSS show transport properties that are not directly predictable with simple correlations from the properties of the components. FTIR spectrum resulted PSS contain functional group of $\mathrm{o}-\mathrm{SO}_{3} \mathrm{H}$ and $\mathrm{p}-\mathrm{SO}_{3} \mathrm{H}$. The highest of Degree of sulfonation was in PSS3 (48.15). Molecule weight of PSS is higher than PS and the PSS membrane have good qualitative test of methanol permeability. The best membrane is PSS3 which have the highest proton conductivity. DMFC system show proton conductivity and electrical current of PSS better than PS. PSS is has potential to be utilized as membrane electrolyte. NMR and AFM showed the PSS membrane has synthesized properly.

\section{ACKNOWLEDGMENTS}

The authors are thankful to:

1) Directorate General Higher Education for providing financial and funding of research international collaboration 2012.

2) Lembaga Penelitian dan Pengabdian pada Masyarakat (LPPM) Institute Pertanian Bogor for his cordial support, valuable information and guidance, which helped us in completing this task through various stages.

\section{REFERENCES}

[1] E. A. Smit, A. L. Ocampo, M. A. Espinosa-Medina, and P. J. Sebastian, "A modified nafion membrane with In situ polymerized polypyrrole for the direct methanol fuel cell," Journal of Power Sources, vol. 124, pp. 59-64, 2003.

[2] Y. Woo, S. Y. Oh, Y. S. Kang, and B. Jung, "Synthesis and characterization of sulfonated polyimide membranes for direct methanol fuel cell," Journal of Membrane Science, vol. 220, pp. 31-45, 2003.

[3] P. Xing, P. R. Gilles, D. G. Michael, D. M. Serguei, W. Keping, and K. Serge, "Synthesis and Characterization of Sulfonated Poly(ether ether ketone) for proton exchange membranes," Journal of Membrane Science, vol. 229, pp. 95-106, 2004.

[4] P. P. Kundu, V. Sharma, and Y. G. Shul, "Composites of proton-conducting polymer electrolytemembrane in direct methanol fuel cells," Crit. Rev. Solid State Mater. Sci., vol. 32, no. 51, 2007.

[5] V. Neburchilov, J. Martin, H. Wang, and J. Zhang, "A review of polymer electrolyte membranes for direct methanol fuel cells," $J$. Power Sources, vol. 169, pp. 221, 2007.

[6] H. Pei, L. Hong, and J. Y. Lee, "Embedded polymerization driven asymmetric PEM for direct methanol fuel cells," J. Membr. Sci., vol. 270, pp. 169, 2006.

[7] H. J. Meier, A. Taeger, C. Vogel, K. Schlenstedt, W. Lenk, and D. Lehmann, "Membranes from sulfonated block copolymers for use in fuel cells," Sep. Purif. Technol., vol. 41, pp. 207, 2005.

[8] R. T. S. M. Lakshmi, H. J. Meier, K. Schlenstedt, C. V. V. Choudhary, and I. K. Varma, "Sulphonated poly (ether ether ketone) copolymers: Synthesis, characterization and membrane properties," Journal of Membrane Science, vol. 261, pp. 27-35, 2005.

[9] S. D. Mikhailenko, K. Wang, S. Kaliaguine, P. Xing, G. P. Robertson M. D. Guiver, "Proton conducting membranes based on cross-linked sulfonated poly (ether ether ketone) (SPEEK)," Journal of Membrane Science, vol. 233, pp. 93-99, 2004.

[10] M. Han, G. Zhang, K. Shao, H. Li, Y. Zhang, and M. Li, "Carboxyl terminated benzimidazole-assisted cross-linked sulfonated poly (ether ether ketone)s for highly conductive PEM with low water uptake and methanol permeability," J. Mater Chem., vol. 20, pp. 3246-3252, 2010.

[11] M. Kulkarni, R. Potrekar, R. A. Kulkarni, and S. P. Vernekar, "Synthesis and characterization of novel polybenzimidazoles bearing pendant phenoxyamine groups," J. Polym Sci. Part A Polym Chem., vol. 46, pp. 5776-5793, 2008.

[12] D. Mecerreyes, H. Grande, O. Miguel, E. Ochoteco, R. Marcilla, and I. Cantero, "Porous polybenzimidazole membranes doped with phosphoric acid: highly proton-conducting solid electrolytes," Chem. Mater, vol. 16, pp. 604-607, 2004.

[13] J. Weber, K. Kreuer, J. Maier, and A. Thomas, "Proton conductivity enhancement by nanostructural control of poly (benzimidazole)-phosphoric acid adducts," Advance Material, vol. 20 , pp. 2595-2598, 2008.

[14] S. M. J. Zaidi, S. D. Mikhailenko, G. P. Robertson, M. D. Guiver, and S. Kaliaguine, "Proton conducting composite membranes from polyether ether ketone and heteropolyacids for fuel cell applications," $J$. Membrane Science, vol. 173, pp. 17-34, 2000.

[15] D. S. Kim, G. P. Robertson, Y. S. Kim, and M. D. Guiver, "Copoly (arylene ether)s containing pendant sulfonic acid groups as proton exchange membranes," Macromolecules, vol. 42, pp. 957-963, 2009.

[16] D. J. Jones and J. Roziere, "Recent advances in the functionalisation of polybenzimidazole and polyetherketone for fuel cell applications," $J$. Membr. Sci. vol. 185, pp. 41, 2001.

[17] A. F. Ismail, N. H. Othman, and A. Mustafa, "Sulfonated polyether ether ketone composite membrane using tungstosilicic acid supported on silica-aluminium oxide for direct methanol fuel cell (DMFC)," Journal of Membrane Science, vol. 329, pp. 18-29, 2009.

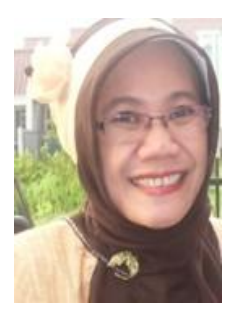

S. Mulijani received her first degree of Science in Chemistry from Padjadjaran Universiti Indonesia in 1988, master of Science in Chemistry (Inorganic Material) from Institute Technology Bandung Indonesia in 2000, and Ph.D. Program of Material Science in University of Indonesia Jakarta Indonesia in 2009. She starts working at Chemistry Department Bogor Agriculture University as a Chemistry and Material Science lecturer from 1991 until now.

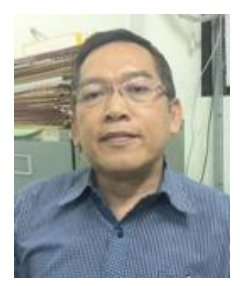

K. Dahlan received his degree of Science in Physycs from Institute Technology Bandung Indonesia and Ph.D. from University New South Wales Australia in 1995, and he starts working at Physics Department Bogor Agriculture University Indonesia as a Physics Science lecturer from 1987.

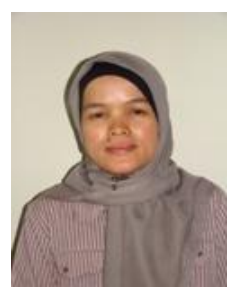

A. Wulanawati received her degree of Science in Chemistry from Institute Technology Bandung and master Program from University of Indonesia. She has been working at Chemistry Department as a lecturer of Chemistry Science since 2005. 